\title{
Writing Through the 4Cs in the Content Areas - Integrating Creativity, Critical Thinking, Collaboration and Communication
}

\author{
Randa Saliba Chidiac \\ Laurence Ajaka \\ Holy Spirit University of Kaslik, Lebanon
}

Doi: 10.19044/esj.2018.c4p8 URL:http://dx.doi.org/10.19044/esj.2018.c4p8

\begin{abstract}
Writing is a complex process that involves a number of competences and a degree of imagination. It can be evolved by using the $4 \mathrm{Cs}$ in the content areas: integrating creativity, critical thinking, collaboration, and communication, all of which teachers have struggled to include as part of their curricula. These struggles are often caused by logistic and financial constraints. With the professional demand pressingly navigating towards technology, teachers can aid their students by applying solution amenable to immediate use, low cost and tolerates interdisciplinary implementation. The first step would be to abandon the conventional curricula that were taught before as most of the current students are at a whole new technological level. They can be replaced by more pertinent skills that cater to the artistic and professional outlooks of students. This will ultimately equip them to be able to meet the market standards and improve their vocational prospects.
\end{abstract}

Keywords: Education, 4Cs, creativity, critical thinking, collaboration, communication, technology, implementation

\section{Introduction}

Writing is one of the hardest skills to foster because it involves the concentration and distillation of various linguistic aptitudes such as grammar and vocabulary as well as having a decent imagination that allows an unconstructive flow of ideas. It is now considered an important skill in almost all domains (Klimova, 2015) as the world is becoming more technologically inclined and people often need to communicate with others who belong to different cultures. Students struggle with utilizing their acquired knowledge and using it in writing (Hyland, 2013). At lower levels, teachers seem to focus on receptive language skills such as reading and listening instead of productive language skills such as speaking and writing (Sebestova, Najvar \& Janik, 
2011). Among the higher levels of education, students struggle with weak arguments, elaboration, integration of prior knowledge, and lack of critical thinking (Cavdar \& Doe, 2012). This makes it difficult to generate content as well as evaluate what they have written.

One of the approaches that aid students in developing their writing skills is integrating the 4Cs in writing content areas. They are creativity, critical thinking, collaboration, and communication. This paper explores the benefits of these skills as well as the most cost-effective and efficient methods of integrating them into the curricula. This paper is a practical approach for each teacher that can easily be adopted without any drastic changes that can prove to be impractical for budget reasons or opposition from administrative authorities. It contains tips that any teacher can reasonably include within any curricula.

\section{Creativity}

Although creativity can be simplified as "making something original", it is in of itself a very complicated process (Yates \& Twig, 2017). Adults often grow up being afraid of creativity as a whole concept because they are not given the proper tools to develop that skill at an early age. Some of the theories that explain this gap explain that the activities given to children are often controlled by adults. For example, during Arts \& Crafts in school, children are asked to paint a picture or build some kind of model. Though they might aid some skills, creativity is not necessarily improved by them because they tend to a pre-determined outcome instead of allowing children the freedom to exercise their vision (Myhill \& Wilson, 2013).

Creativity necessitates breaking loose of all the restrictions and expectations in order to forge something new and unique. Wright (2015) also pointed out that shaping children's creativity is often limited by the educator's ability to stimulate said instructor's own creative capabilities that are often lacking due to the accumulation of practices and policies that failed to nurture this skill. It seems that the educators themselves need to be rehabilitated in the art of teaching their charges at the various stages of education. Due to this lack, teachers fail out of the fear of the unexpected (Cheung, 2013). They would lean towards the expected and discourage the unique, and they even go further by relating a lively imagination to psychological problems.

There is much to be learned from children when it comes to creativity. A closer look at children reveals individuals who are carefree and independent thinkers (Glaveanu, 2011). They draw, dance and even create imaginary friends with little heed to the laws of the world around them. That flexibility should be encouraged rather than stifled by teachers. They need to ask children questions that provoke further explanations, and the more bizarre the better. This technique might not work so well with older students, but that dormant 
part can be triggered as well. Music is an attractive option because it is something that can be interpreted differently. The Internet offers a wealth of options; teachers should not feel restricted to the classical pieces and they could dive into a wealth of ethnic music. Eliminating words or the understanding of words is further incentive for creativity. Furthermore, narration is a great option for inducing creativity. Teachers can start off small by telling a story and asking children to provide the ending. For older students, teachers can present an unusual premise; for example: What would happen if Earth lost its gravity and we were all floating all the time? Is there really a cat conspiracy to take over the world? If these prompts seem outlandish then that's the point.

Creativity tiptoes the line between sanity (our comfort zone) and insanity (uncharted waters), so the more boundaries are pushed, the more creative our students can become.

\section{Critical Thinking}

Critical thinking is another elusive quality that we wish to cultivate in our students yet we often fall short on that goal. It is also incredibly difficult to define a concept as fluid as critical thinking because it is as changeable as the situation presented. Critical thinking is centered on updating existing knowledge by analyzing new situations through performing comparisons, establishing relationships, extracting new ideas and evaluating truth, utility and consequences of findings (Florea \& Hurjui, 2015). If this sounds too complex, think of critical thinking as a method or tool that allows students to fix problems in a logical, albeit not always conventional, way.

As mentioned before, students might have plenty of knowledge about a topic, but they are incapable of translating that knowledge into viable information. According to Bailey et al. (2015), some of the most common problems of writing are weak or no evaluation of theoretical assumptions, disorganized structural formation, weak support for ideas and lack in the ability to critique. This is because children are always taught the answers but never the questions. Some of the drawbacks of the educational system in-place are that it encourages memorization of facts and figures instead of exploring knowledge.

Critical thinking is a topic that some teachers willfully chide away from because they are afraid it will make compromise their position as the source of all the answers. Critical thinking has to be about finding links between unlikely sources. This will all start off by encouraging children to start off conversations with one another. Let them argue among themselves about what makes sense and what doesn't. With their active imagination and creativity, they will find unlikely connections that an adult would never have thought about. To further assist in establishing these links, present them into 
something tangible such as a flowchart. For older students, a simple and effective method is to build their ability to ask questions instead of providing answers. The father of critical thinking Socrates himself was always more concerned with the question instead of the answer. Write a sentence on the board and students think back on the path that would have led to this outcome. Trying to reconstruct the pathway to the answer is more challenging and it forces students to find correlations and a logical sequence for the outcome. Teachers can instigate the conversation and keep its flow by laying the devil's advocate and asking all sorts of questions. Such discussions might be hindered by a tight curriculum, so they can be done during brainstorming sessions of writing. Once students are versed, they can be given as homework. Teachers should keep in mind that some students may be too shy to voice their opinions especially when they could be contested by their peers, so a good tip to encourage them would be by roleplaying. By putting them in the position of someone else, they are more likely to voice their own ideas because they now have a suitable mouthpiece.

For critical thinking to flourish, there needs to be little restriction on what students want to ask or think which could be challenging in a contested environment we live in. To minimize the friction, deal with any controversy calmly and make sure you present a neutral global topic that will never trigger the sensibilities of different characters and backgrounds.

\section{Collaboration}

The aspect of collaboration is taking on more importance in today's world with the bloom of the Internet and online teaching. Collaborative writing can be an asset for students because they are involved with others during all the stages of writing. It can be defined as "An activity where there is a shared and negotiated decision-making process and a shared responsibility for the production of a single text" (Storch, 2013). While writing is stressful for all age groups, it can be particularly taxing for those in grade 11 and 12 who face many assessment tests that can influence their college careers. They are also taught writing techniques specific to university and therefore have to quickly adapt their personal styles.

In a study conducted by Vorobel \& Kim (2017), they discovered that collaborative writing developed the communication skills through discussions, negotiation and developing arguments on one hand and produced a text of a higher quality in terms of organization, grammar, and vocabulary on the other hand. For students who deal with English as a second language, it is beneficial that students perform their own discussion in English to consolidate their benefit from the activity as well as enhancing the produced text (Wigglesworth \& Storch, 2012). 
Collaboration can be a bit difficult for some students who do not have the best communication skills, so teachers need to make sure they create an inclusive environment. Collaboration's first step involves splitting students into groups made up of students with different skills and personalities because collaboration is all about merging the strengths of every member to cover up their deficiencies. In fact, putting together students with similar skills will only create some problems as each will try to up do the other and taking the lead. With different strengths, each of the students will have their own spotlight which will boost their morale and allow them to become more engaged. These groups will revolve around having the right dynamic to evolve so make sure you keep tabs and make sure balance and open communication exists between every member of the group.

The instructor should also provide students with the tools to properly critique their own work and that of others. Students do not have the proper vocabulary and technique to address the issues of what was written and often use terms such as "stupid" and "wrong". This is never helpful because it either creates anger from the person critiqued or makes them drawn within themselves and put halt to further contribution they might have had. The instructor can perform critiquing exercises by telling students to read aloud passages from other sources and encouraging them to express their feelings and opinions. Their expressions at first will be unsophisticated, but the instructor can modulate these expressions in a way that allows them to pinpoint whatever deficiencies they perceive and thus work out methods of improving them. This will, in turn, enhance their critical thinking skills and communication tools. It supplies them with a way to properly articulate their opinions and thus allow all members of the group to collaborate more efficiently and effectively.

\section{Communication}

The age of computers has further pushed the boundaries of communication where the written letter takes precedence over body language and tone; however, communication has always been an integral part of the classroom (Sirbu \& Tonea, 2015). The role of the teacher is vital because they have to manage the entire environment by planning, organizing and motivating students to communicate with one another. Furthermore, the new curricula have pushed students to become a more active component in the learning process, so they now need to have the communication tools to occupy the center stage position that was traditionally restricted to teachers (Yusof \& Halim, 2014).

Teachers' fostering communication in the classroom will serve three main purposes: stimulate the relevant knowledge from the students that have previously acquired the information but are unable to correlate it to the 
question, allow them to interact with what is being discussed by others and be able to properly describe what experiences with others to add their own input and impact on the discussion (Farrell, 2009). The onslaught of digital communication has robbed this generation from much of the opportunities that have allowed previous generations to cultivate the hone their own style as they are too immersed in the online world. They find it difficult to write in a way that expresses their opinion.

The problem is twofold: communicating with others verbally and communicating in the written word. The verbal communication can be enhanced by referring to collaboration in chapter 3. Having students work in groups with their peers is the first step because it removes any position leverage and forces them into a situation where they could be on equal footing and capable of voicing their opinions. As mentioned before, the teacher needs to step in and supply them with the proper tools and words that allow them to critique what has been said instead of focusing on criticizing it.

When it comes to written communication, there are several tips that can aid students. The number one step is to carefully pinpoint the focal idea as students often get confused about what to write. They have all the knowledge of the world at their fingertips, so they are loaded with too much material to choose from. Focusing on the idea would mean less confusion for them and remove some of the panics at the prospect of not being able to properly cover the entire topic.

The younger generation can benefit a lot from including games in the writing process. It is not always about putting a video game or power point presentation on the board for them to see as this is not available in all schools. Games can be written on the board or created on paper or cardboard and are passed to students. Games are engaging for children and even those most averse to writing or participating might communicate. Games also have the added advantage of being extremely interactive, so they create open communication channels between all involved.

Students should also learn to write clearer. Help them to write in small and clear sentences as they seem to think that only by writing compound and complex sentences they can get a better grade. This often backfires on students because it weakens their structure. Instead, encourage them to use simple sentences with power adjective, adverbs, and images that will get their point across clearly and concisely. Teachers should stress that writing at the level of the university is all about getting a message across clearly rather than flowery and redundant expressions. They should be extremely careful of using ambiguous language that can be interpreted in a different way. Again and again reading out loud and having other comment and address what was written goes a long way towards improving the overall text. 


\section{Conclusion}

The 4 Cs, creativity, critical thinking, collaboration and communication can play an integral part of writing in today's curricula. By implementing these techniques, you can stimulate the students' creativity and imbue them with the tools needed to facilitate the writing process.

Today's curricula are challenged by the need to incorporate new technology to cater for the thinking process of the generation who has abandoned even the notion of letters and words for pictures and emojis making the concept of writing alien to most of them. Even within the space of their working careers, they will be required to present detailed and well-constructed reports of their work. Hence, writing is an important skill that is now an essential requirement in all the wakes of life. They can benefit from the 4Cs being integrated within the curricula to spark their interest and facilitate their journey into writing. They have been scientifically proven to benefit individuals in acquiring a number of skills in many domains including writing. The creativity can be stocked by stripping away the constraints of words and replacing them with thoughts. Critical thinking is enhanced by having students work on their logical thinking and analysis. They can benefit from collaboration by joining together those with different skills and having them learn from their peers. Their communication skills can be enhanced by focusing on clear and concise ideas and sentences rather than frills. Even though many have claimed that everything under the sun has been written already, others believe that there are many untold stories waiting the perfect conduit to burst through.

\section{References:}

1. Bailey, A. et al. (2015). Building a scholar in writing (BSW): A model for developing students' critical writing skills. Nurse Education in Practice, 15 (2015) 524e529

2. Çavdar, G., Doe, S., 2012. Learning through writing: teaching critical thinking skills in writing assignments. PS Polit. Sci. Polit. 45, $298 \mathrm{e} 306$.

3. Farrell, T. S. (2009).Talking, listening, and teaching: A guide to classroom communication. Canada: Corwin.

4. Florea, N. \& Hurjui, E. (2015). Critical thinking in elementary school children. Social and Behavioral Sciences, 180 ( 2015 ) 565 - 572

5. Glaveanu, V. (2011). Children and creativity: A most (un)likely pair? Thinking Skills and Creativity, 6 (2011) 122-131

6. Hyland, K., 2013. Writing in the university: education, knowledge and reputation. Lang Teach. $46,53 \mathrm{e} 70$

7. Klimova, B. (2015). Teaching English Abstract Writing Effectively. Social and Behavioral Sciences, 186 ( 2015 ) pp. 908 - 912 
8. Myhill, D., \& Wilson, A. (2013). Playing it safe: Teachers' views of creativity in poetry writing. Thinking Skills and Creativity, 10, 101111. http://dx.doi.org/10.1016/j.tsc.2013.07.00

9. Sebestova, S., Najvar, P., \& Janik, T. (2011). Prilezitosti k rozvijeni recovych dovednosti ve vyuce anglickeho jazyka: samostatne anebo v integraci. Pedagogicka orientace, 21(3), 322-348.

10. Sirbu, C. \& Tonea, E. (2015). Teachers' management roles in the development of communication skills. Social and Behavioral Sciences, 174 ( 2015 ) 3948 - 3952

11. Storch, N. (2013). Collaborative writing in L2 classrooms (vol. 31). Multilingual matters

12. Wigglesworth, G. \& Storch, N. (2012). What role for collaboration in writing and writing feedback. Journal of Second Language Writing, 21 (2012) 364-374

13. Wilson, A. (Ed.). (2015). Creativity in primary education. London: Sage

14. Yates, E. \& Twig, E. (2017). Developing creativity in early childhood studies students. Thinking Skills and Creativity, 23 (2017) 42-57

15. Yusof, F. \& Halim, H. (2014). Understanding Teacher Communication Skills. Social and Behavioral Sciences, 155 ( 2014 ) 471 - 476 